\title{
Development of transplanting manipulator for hydroponic leafy vegetables
}

\author{
Bo Li ${ }^{1}$, Song $\mathrm{Gu}^{1,2^{*}}$, Qi Chu ${ }^{3}$, Yanli Yang ${ }^{3}$, Zhongjian Xie ${ }^{1}$, Kaijun Fan ${ }^{1}$, Xiaogeng Liu ${ }^{1}$ \\ (1. College of Engineering, South China Agricultural University, Guangzhou 510642, China; \\ 2. Key Laboratory of Key Technology on Agricultural Machine and Equipment, Ministry of Education, \\ South China Agricultural University, Guangzhou 510642, China; \\ 3. Guangzhou Sky Mechanical \& Electrical Technology Co., Ltd, Guangzhou 510642, China)
}

\begin{abstract}
The production of hydroponic leafy vegetable plug-seedlings uses coco-peat as culture substrate in South China. Coco-peat has lowered density than peat-moss, and the friction between substrate block and pickup tool is small. So, it is hard to pick up in mechanism transplantation. In order to increase the friction, the existing transplanting manipulator had relatively complex structures. To simplify the structure of transplanting manipulator and improve the stability of picking up substrate block, four stainless steel fingers with rectangular cross-section were used in this research. A vertical driving was used to realize the coupling effect that could insert and shrink at the same time, by applying different combination of constraints to the steel fingers. This could increase friction between the steel fingers and the substrate block, and then enhance the stability of the substrate block. Different combinations of constraints were applied to the rectangular stainless steel fingers $(3 \mathrm{~mm} \times 0.8$ $\mathrm{mm})$. The working videos of steel fingers were taken by high-speed photography. High-speed motioned analysis software was used to acquire and analyze traces of steel fingers movements. When the length which top end of the steel fingers moved outward $(M)$ is equal to $1.5 \mathrm{~mm}$, the length which guiding part widened $(N)$ is equal to $1 \mathrm{~mm}$, the shrinking distance of steel fingers is $4.2 \mathrm{~mm}$. In this research, 16-day hydroponic leafy vegetable plug-seedlings were used for performance, which cultivated with coco-peat substrate with the moisture in the substrate at $81 \%$. The transplanting manipulator was attached to a Denso robotic arm to conduct transplanting performance test. When the shrinking distance of steel fingers increased from $0 \mathrm{~mm}$ to $3.2 \mathrm{~mm}$ and the inserting angle decreased from $80^{\circ}$ to $77^{\circ}$, the lifting force of substrate block increased by $118 \%$ from $1.45 \mathrm{~N}$ to $3.16 \mathrm{~N}$. However, excessive shrinkage stirred the substrate block, which would reduce the friction between the substrate block and pickup parts and lowered the lifting force of pickup part in the substrate block. The experimental results also demonstrated that when the shrinking distance of the steel fingers reached $3.2 \mathrm{~mm}$ and the root distribution rate reached $46 \%$, the success rate of transplantation was $80 \%$. When the leafy vegetable plug-seedlings root distribution rate reached $92 \%$, the success rate of transplantation was $96.67 \%$. The degree of root distribution rate was positively correlated with the transplantation success rate. Therefore, in order to ensure an acceptable success rate of transplantation, the root distribution rate of leafy vegetable plug-seedlings should be at least $90 \%$. This study provides a technical reference for developing simplified transplanting manipulator that can be used to transplant the hydroponic leafy vegetable plug-seedlings with coco-peat as the culture substrate.
\end{abstract}

Keywords: transplanting robot, transplant manipulator, steel fingers, hydroponic leafy vegetable plug-seedlings, high-speed photography, guidance constraints, shrinkage

DOI: $10.25165 /$ j.ijabe.20191206.5050

Citation: Li B, Gu S, Chu Q, Yang Y L, Xie Z J, Fan K J, et al. Development of transplanting manipulator for hydroponic leafy vegetables. Int J Agric \& Biol Eng, 2019; 12(6): 38-44.

\section{Introduction}

Hydroponic leafy vegetables have the advantages of low

\section{Received date: 2019-03-31 Accepted date: 2019-10-31}

Biographies: Bo Li, PhD candidate, research interests: modern horticultural production intelligent equipment, Email: bolee0086@sina.com; Qi Chu, PhD, research interests: modern horticultural production intelligent equipment, Email: 452944632@qq.com; Yanli Yang, PhD, research interests: modern horticultural production intelligent equipment, Email: 867801351@qq.com; Zhongjian Xie, PhD candidate, research interests: modern horticultural production intelligent equipment, Email: 294580211@qq.com; Kaijun Fan, Master candidate, research interests: modern horticultural production intelligent equipment, Email: 534386753@qq.com; Xiaogeng Liu, Master candidate, research interests: modern horticultural production intelligent equipment, Email: 1015306360@qq.com.

*Corresponding author: Song Gu, PhD, Professor, research interests: modern horticultural production equipment. South China Agricultural University, Guangzhou 510642, China. Email: sgu666@sina.com. pollution, high yield, and good quality. So, it is suitable for the large-scale cultivation in controlled environment greenhouses ${ }^{[1-3]}$. Large-scale production of hydroponic leafy vegetables requires transplanting large leafy vegetable plug-seedlings, which is costly and time-consuming ${ }^{[4-8]}$. In addition, rising labor costs makes this process more expensive ${ }^{[9-13]}$. Therefore, it is important to develop new horticulture facilities that fit the demand of Chinese hydroponic leafy vegetables production ${ }^{[14,15]}$.

Transplanting manipulator is a key component of automatic transplanting equipment. Cultivate substrate coco-peat is widely used during cultivating hydroponic leafy vegetable plug-seedlings, due to its low density compared with peat-moss. It is important to shrink and compress the substrate block to increase the positive pressure on the steel finger, and enhance the friction force between the steel finger and the substrate block, in another word, to improve the stability of picking and carrying substrate blocks.

Kutz et al. ${ }^{[16-19]}$ studied the transplanting manipulator based on 
industrial robots in the 1980s and 1990s. In recent years, the inclined-inserting transplanting manipulator developed by Gao et al. ${ }^{[20]}$ could increase the friction force by rising the positive pressure on the substrate block, but the transplanting manipulator was large. $\mathrm{Hu}$ et al. ${ }^{[21]}$ and some enterprises ${ }^{[22,23]}$ in Europe have adopted a deformed sliding needle-type transplanting manipulator, which can guide the steel finger deformation through the duct to reach required angle. However, the restorative force originating from the steel finger deformation causes greater friction between the steel finger and duct. Visser ${ }^{[22]}$, Jiang et al. ${ }^{[24,25]}$, and Han et al. ${ }^{[26-28]}$ adopted dual drivers that led to two actions of steel finger. However, this dual-drive system led to more complicated structure of the transplanting manipulator. In order to simplify the complex structure of dual drive, Zhang et al. ${ }^{[29]}$ and Feng et al. ${ }^{[30]}$ used single drive to achieve the steel finger insertion and shrinking the substrate block, but the structure of the transplanting manipulator was still not simple. Through our investigation, the major transplanting machine manufacturers in the developed countries in Europe simplified the transplanting manipulator structure to lower the operation failure rate ${ }^{[31-34]}$, such as TTA, Flier, Tea, Dalos and Ubinati.

This research used the coco-peat with small density, which is commonly used in the production of hydroponic leafy vegetable plug-seedlings. With an insert along with shrink method that simple structure was designed to realize the steel finger' insertion and shrinking driven by a sole cylinder. In this study, the hydroponic leafy vegetables' parameters was obtained, such as stem and leaf sizes, root system distribution, and plug seedling pulling force, and designed the transplanting manipulator accordingly. High-speed photography and high-speed motioned analysis software were used to track and analyze the movement of the points on steel fingers. The structural parameters of the transplanting manipulator were optimized. The operation parameters of the transplanting manipulator were optimized through the performance test of the transplanting manipulator, which provided a technical reference for the development of automatic transplanting machines for leafy vegetable plug-seedlings cultivated by coco-peat.

\section{Parameters of hydroponic leafy vegetable plug-seedlings}

The common hydroponic leafy vegetable plug-seedlings with 16-day seedling and 2.5 true leaves were used in this research. Plant height, and crown width were measured for Chinese pakchoi, Lvbao kale, Guangfu no.1 flowering cabbage, Italy elite lettuce, and Boston butter lettuce. ARK-10M4-20 type dynamometer was used to test the pulling force of plug-seedlings. It used clamp to hold and pull the plug-seedlings out with the loading speed $1 \mathrm{~mm} / \mathrm{s}$. The moisture content of the substrate block was $81 \%^{[14]}$ and the test was repeated for 30 times. The root distribution rate of various seedlings was measured and expressed as the rate of the root distribution area on the side of the substrate block divided the area on the side of the substrate block. 100 seedlings were measured for each breed. As shown in Table 1, Chinese leafy vegetables are all larger than European leafy vegetables, with 19\%-77\% higher in the plant height, $17 \%-66 \%$ wider in the crown width, and $100 \%-111 \%$ larger in the root distribution rate.

Table 1 Parameters of five common leafy vegetable plug-seedlings

\begin{tabular}{ccccc}
\hline & \multicolumn{4}{c}{ Parameter } \\
\cline { 2 - 5 } Breed & $\begin{array}{c}\text { Plant } \\
\text { height } \\
/ \mathrm{mm}\end{array}$ & $\begin{array}{c}\text { Crown } \\
\text { width } \\
/ \mathrm{mm}\end{array}$ & $\begin{array}{c}\text { Root } \\
\text { distribution } \\
\text { rate/\% }\end{array}$ & $\begin{array}{c}\text { Pulling force of } \\
\text { plug-seeding } \\
/ \mathrm{N}\end{array}$ \\
\hline Chinese pakchoi & $69.7 \pm 10.2$ & $58.2 \pm 14.7$ & $80 \pm 4.6$ & $0.9 \pm 0.3$ \\
Lvbao kale & $65.9 \pm 10.2$ & $47.0 \pm 3.5$ & $85 \pm 5.2$ & $1.1 \pm 0.4$ \\
Guangfu no.1 & $77.7 \pm 16.7$ & $78.6 \pm 24.5$ & $92 \pm 3.5$ & $1.6 \pm 0.5$ \\
flowering cabbage & & & & \\
Italy elite lettuce & $65.4 \pm 15.5$ & $47.3 \pm 14.6$ & $46 \pm 5.1$ & $0.6 \pm 0.2$ \\
Boston butter lettuce & $37.2 \pm 8.3$ & $40.3 \pm 12.4$ & $38 \pm 4.2$ & $0.4 \pm 0.2$ \\
\hline
\end{tabular}

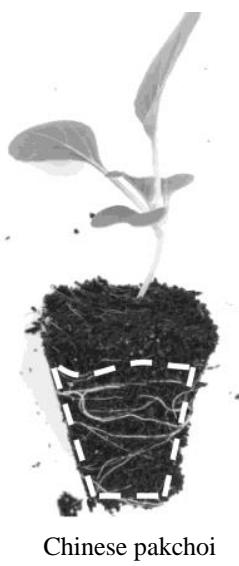

Chinese pakchoi

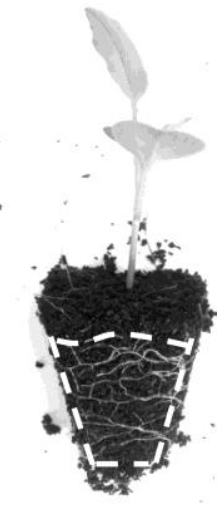

Lvbao kale

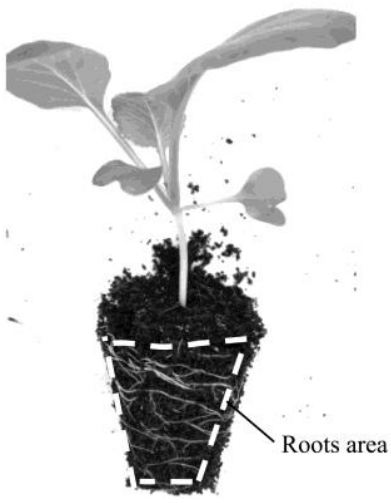

Guangfu no.1 cabbage

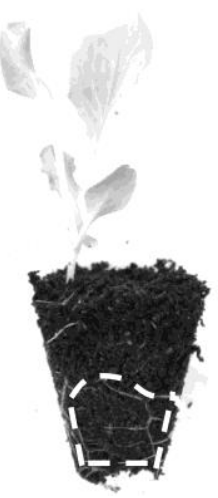

Italy elite lettuce

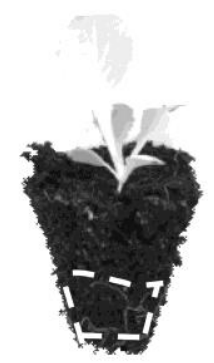

Boston butter lettuce

Figure 1 Geometric feature of leafy vegetable seedlings

\section{General working principles}

\subsection{Transplanting system}

Figure 2 shows the hydroponic leafy vegetable plug-seedling transplanting system composed of a hydroponic leafy vegetable plug-seedling transplanting robot, a culture duct and a conveying line of culture duct. The transplanting robot is mainly composed of a seedling tray feeding device, a transplanting manipulator, a transplanting manipulator driving device, and a frame. The seedling tray feeding device can determine the position and convey of the seedling tray. A transplanting manipulator driving device is used to transfer seedlings between the seedling tray and the culture duct. A group of transplanting manipulators picks up the seedlings from the seedling tray, transfer seedlings, and place the seedlings into the planting hole of culture duct. The transplanting manipulator group can transplant six seedlings each cycle.

\subsection{Transplanting manipulator}

Transplanting manipulator can pick up plug-seedlings of hydroponic leafy vegetable from seedling tray, and then place them into culture duct using steel fingers (Figure 3 ). 


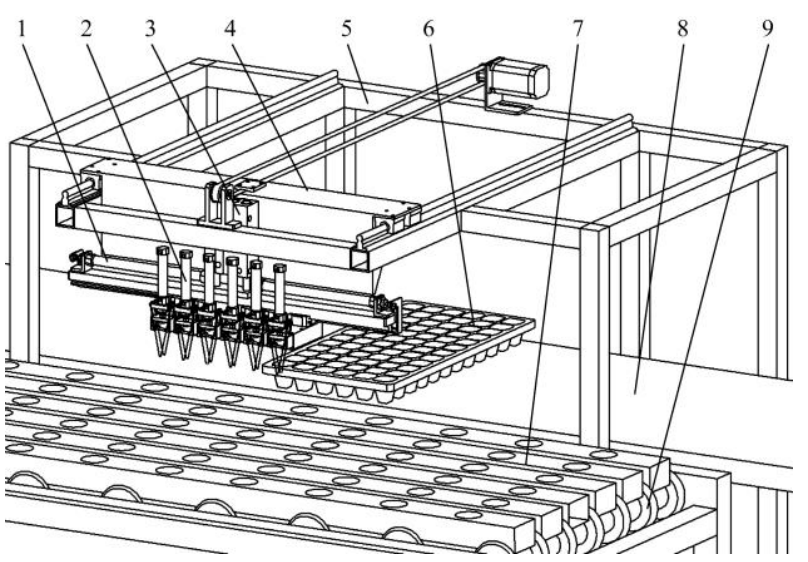

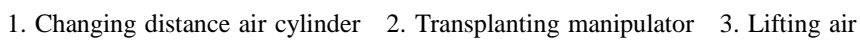
cylinder 4. Horizontal moving unit of transplanting manipulator 5. Frame 6. Seedling tray $\quad$ 7. Culture duct 8 . Delivery belt of seedling tray 9 . Delivery unit of culture duct

Figure 2 Structure of transplanting system for leafy vegetable seedlings

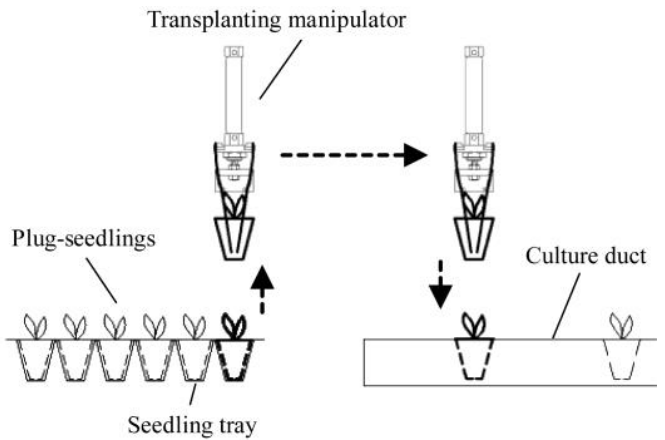

Figure 3 Operation process of transplanting manipulator

\section{Design of transplanting manipulator}

\subsection{Operating demand}

As shown in Table 1, the parameters of transplanting objects are as follows. The maximum plant height is $94.4 \mathrm{~mm}$, maximum crown width is $103.1 \mathrm{~mm}$, seedling age is 16-day, and with 2.5 true leaves. 72-cell seedling tray is widely used in China for hydroponic leafy vegetable production. As shown in Figure 4, the plug tray has length at $540 \mathrm{~mm}$, width at $280 \mathrm{~mm}$, height at $45 \mathrm{~mm}$, cells spacing at $43 \mathrm{~mm}$, cell top size at $38 \mathrm{~mm} \times 38 \mathrm{~mm}$, cell bottom size at $21 \mathrm{~mm} \times 21 \mathrm{~mm}$, and inclination angle of cell wall at $80^{\circ}$. Coco-peat was used as culture substrate for leafy vegetable plug-seedlings with particle size ranging from $1 \mathrm{~mm}$ to $5 \mathrm{~mm}$.
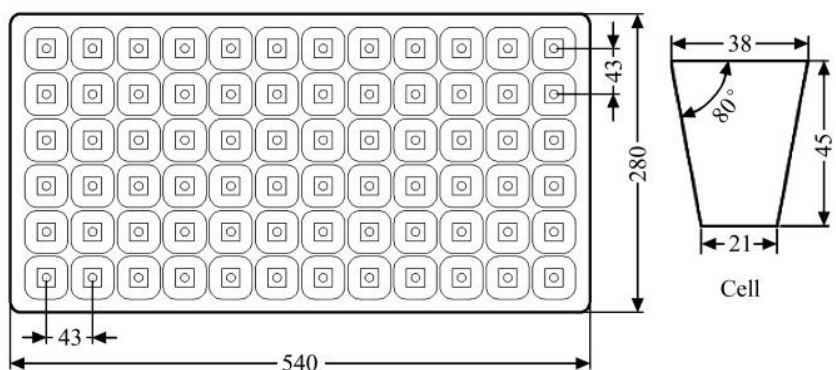

Cell

Figure 4 Size of plug tray

\subsection{Design}

\subsubsection{System design of transplanting manipulator}

As shown in Figure 5a, transplanting manipulator mainly consists of air cylinder block, air cylinder piston pole, guiding part, fixing part and four steel fingers. Fixing part is fastened to air cylinder block and guiding part is fastened to air cylinder piston pole. Top end of steel fingers is fastened to the sides of fixing parts, and four steel fingers insert four square guiding holes of guiding parts. When air cylinder piston pole is pushed out, four fingers are drawn back by air cylinder block. When air cylinder piston pole is pulled in, four fingers are stretched out by air cylinder block.
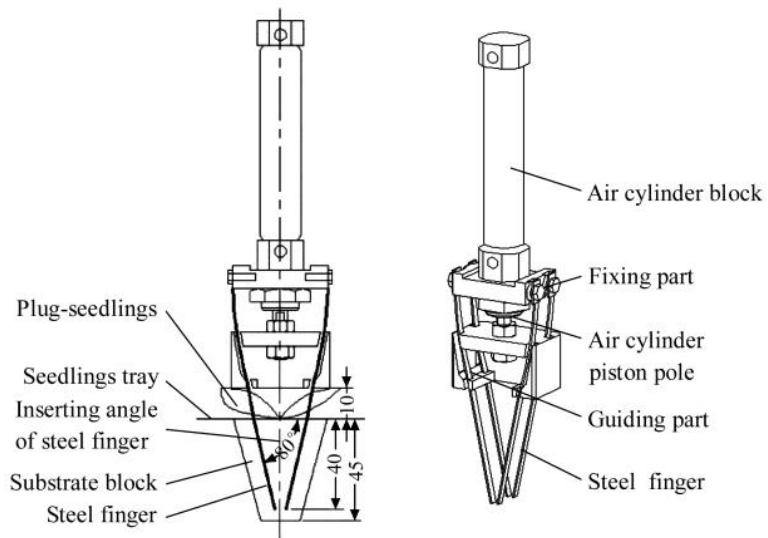

a. Operating height of transplanting manipulator

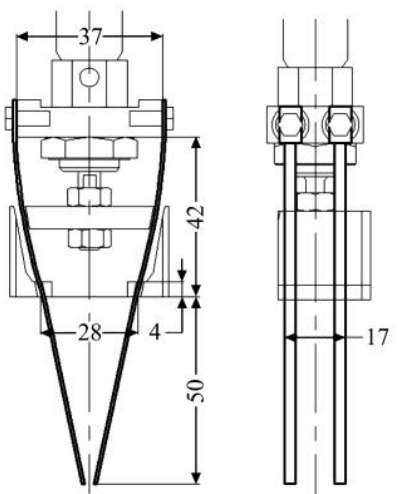

b. Structure size of transplanting manipulator

Figure 5 Design of transplanting manipulator

4.2.2 Inserting angle of steel finger

To prevent damaging seedling tray by steel fingers while the fingers insert into cell walls of seedling trays, inserting angle is set at $80^{\circ}$ which is also the slope of cell wall (Figure 5a).

\subsubsection{Steel finger}

301-stainless steel is used to avoid rusting on steel fingers, and section area is designed into the square shaped to enhance friction with plug seedling. When the width of the steel finger is bigger, the larger perturbation acted on the substrate block. However, if the width of steel finger turning too smaller, the lifting projection area of steel finger on the substrate block will become smaller, and the pressure act on the contact surface will become bigger which leading the substrate block easy to break. Base on previous researches results ${ }^{[14,20,24]}$, when the width of the steel finger is larger than $3 \mathrm{~mm}$, the substrate block is easily fractured by the steel finger, so the width of the steel teeth is set at $3 \mathrm{~mm}$.

When the steel finger is thicker, the larger perturbation acted on the substrate block. On the other hand, thinness steel finger is easy to suffer from deformation when insert into the substrate block, and the deformation will cause great perturbation to substrate block. Through a steel finger deformation test, when the 301-stainless steel size reached $3 \mathrm{~mm} \times 0.8 \mathrm{~mm}$, it can withstand $5 \mathrm{~N}$, which is larger than the pulling force of plug seedling (Table 1). Meanwhile its deformation amount was less than $1 \mathrm{~mm}$ which is smaller than result of 2-3 mm from Zhang et al. ${ }^{[29]}$ Therefore the steel fingers were set at $3 \mathrm{~mm} \times 0.8 \mathrm{~mm}$. 


\subsubsection{Air cylinder}

A preliminary escape-press damaging test was done for the leafy vegetable plug-seedlings. The test result showed that to avoid the damages on the stems and leaves of the leafy vegetable plug-seedlings, the vertical height should be at least $10 \mathrm{~mm}$. Since the height of the steel fingers was $40 \mathrm{~mm}$ (Figure 5a), the vertical moving distance of steel fingers should be $50 \mathrm{~mm}$ as shown in Figure 5b. Finally pen type air cylinder was selected with piston pole diameter at $16 \mathrm{~mm}$ and stroke at $50 \mathrm{~mm}$. The pen-type air cylinders do not need more fixing space.

\subsubsection{Structure of transplanting manipulator}

With the steel fingers inserting angle set at $80^{\circ}$ preliminarily, fixing part width is set at $37 \mathrm{~mm}$ considering cells spacing is $43 \mathrm{~mm}$ which shown in Figure 4. The square guiding holes spacing set at $28 \mathrm{~mm}$ so that $80^{\circ}$ inserting angle could be achieved as shown in Figure 5b. Therefore, the structure of transplanting manipulator has been designed as shown in Figure 5a.

4.2.6 Guiding constraints of steel fingers

If the top end of the steel fingers is moved outward by $M$ and the guiding part is widened by $N$, the steel fingers shrink inward when the steel fingers are inserted downward near the lowest point. In this research, the steel fingers were shrunk inward near the lowest point to clamp substrate block by changing $M$ and $N$. By clamping substrate block, friction between substrate block and steel fingers could be enhanced and lifting force would increase to lift seedlings and its substrate block (Figure 6).
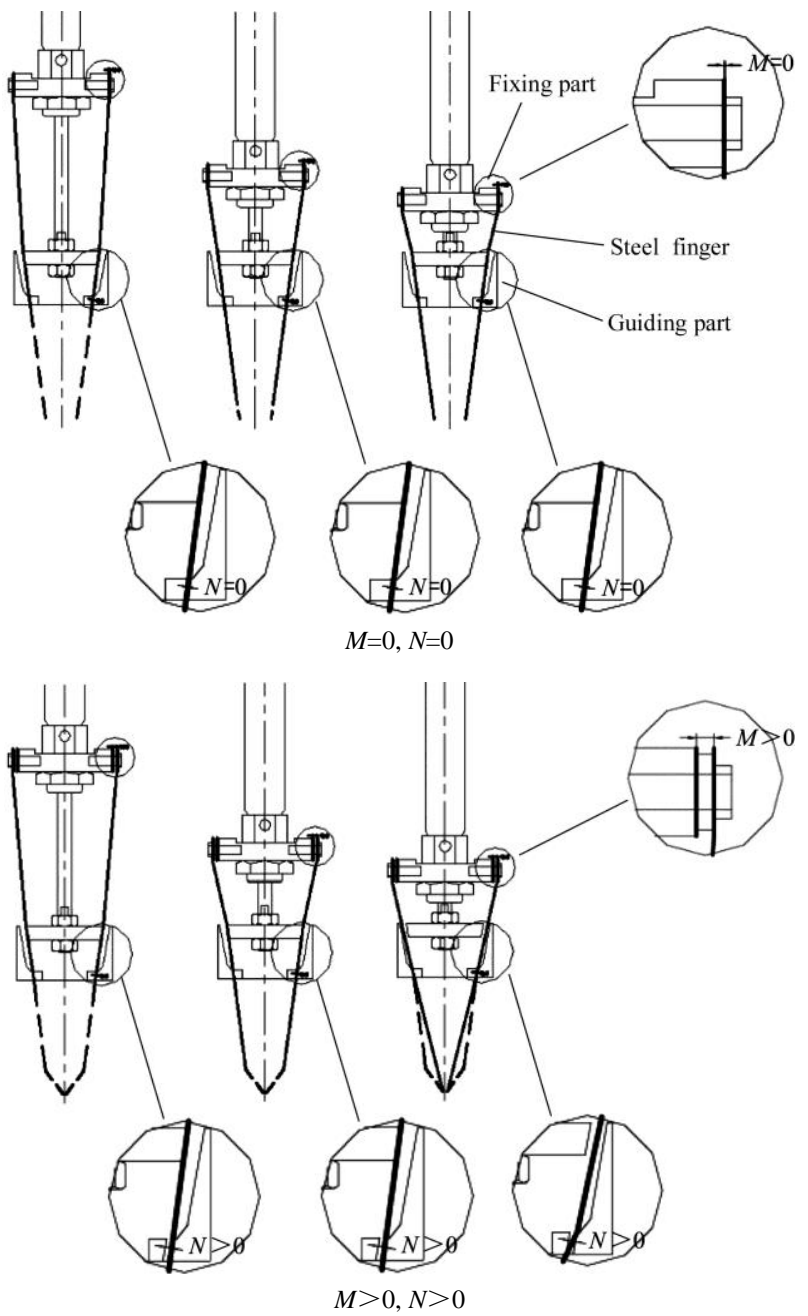

Note: $M$ is the length which top end of the steel fingers moved outward, $N$ is the length which guiding part widened.

Figure 6 Shrinking principles of steel fingers
As shown in Figure 7, the movement traces of points on steel fingers are measured the traces of $a, b, c, d, e$ and $f$ points which change from straight lines into curve lines when $M$ value and $N$ value are changed. The curve traces indicate that the points on steel fingers shrink inward to the center of seedling tray. To determine appropriate shrinking action of steel fingers clamping substrate block, moving videos of steel fingers had been taken with $M$ values at $0 \mathrm{~mm}, 1.5 \mathrm{~mm}$, and $3 \mathrm{~mm}$, meanwhile, $N$ values at $0 \mathrm{~mm}, 0.5 \mathrm{~mm}$, and $1 \mathrm{~mm}$ by using a high-speed camera Revealer 1F005. High-speed motioned analysis software Molysis was used to analyze the movement traces of steel fingers.

Shrinking distance (SD) of steel fingers is defined as the horizontal difference between the end point of steel fingers insert into substrate block when $M$ and $N$ are zero and when $M$ and $N$ are greater than zero. Shrinking distance of steel finger low end point is the biggest, and it decreases as the low end point moving upward. SD results with different $M$ and $N$ combinations were shown in Figure 7.

When $\mathrm{M}$ values and $\mathrm{N}$ values changed, movement traces of steel fingers inserting into substrate block also changed from straight lines to curves. The shrinking distance became larger as the $M$ value getting bigger with $\mathrm{N}$ remaining constant. The same relationship exists between the shrinking distance and $N$ value. When $M=3 \mathrm{~mm}$, it could make both left steel fingers and right steel fingers shrinking about $4.5 \mathrm{~mm}$ inward. If $M>3 \mathrm{~mm}$, left steel fingers would touch right steel fingers before steel fingers reaching the lowest point, causing low part of steel fingers making downward push and stirring substrate block to deteriorate picking condition of substrate. Therefore, with the consideration of both shrinking and stirring, the $M$ value is set as $1.5 \mathrm{~mm}$.

As the $N$ value increases while steel fingers inserting into substrate block and $M$ remains constant, shrink distance at lowest point of steel fingers movement traces is about $1.1 \mathrm{~mm}$ when $N=$ $0 \mathrm{~mm}$, shorter than the shrinking distances when $N$ value is $0.5 \mathrm{~mm}$ or $1 \mathrm{~mm}$. However, the shrinking distances for $N=0.5 \mathrm{~mm}$ and $N=1 \mathrm{~mm}$ are almost the same. Therefore, the $\mathrm{N}$ value is set at $1 \mathrm{~mm}$, considering the shrinking results and stable guiding.

In addition, as the shrinking distances of steel fingers get longer and the inserting angles of lower part of steel fingers get smaller, positive pressure on steel fingers is generated by gravity, leading to higher friction between substrate and cell wall increase and enhanced lifting force on substrate block and seedling.

\section{Transplanting test of transplanting manipulator}

\subsection{Materials and methods}

In order to investigate the transplanting performance of the resulted transplanting manipulator, the manipulator was fixed on a Denso VP-6242E/GM robotic arm, and a transplanting test was carried out to move those 16-day leafy vegetable plug-seedlings from seedling tray into culture duct (Figure 8).

Transplanting success rate (TSR) and lifting force (LF) of plug-seedlings were measured. Transplanting success rate is defined as the ratio of the number of plug-seedlings moved into culture duct and the total number of plug-seedlings. Lifting force is the sum of gravitational force of seeding and substrate block, and a force displayed by force meter, as shown in Figure 9.

The variables in the objective function are shrinking distance (SD) determined by $M$ value and $N$ value, and root distribution rate (RDR) on side of substrate block determined by varieties of leaf vegetable plug-seedlings. As shown in Table 1, $(92 \pm 3.5) \%$, $(80 \pm 4.6) \%,(46 \pm 5.1) \%$ were chosen as high, median and low RDR 
of leafy vegetable plug-seedlings as three different level values. Based on the analysis of $M$ and $N$, and the measuring of SD shown in Figure 7, SD values were chosen as $0 \mathrm{~mm}, 3.2 \mathrm{~mm}$ and $4.2 \mathrm{~mm}$. The level values of SD and RDR was shown in Table 2. The substrate moisture content in this research was set at $81 \%$ based on the research results by $\mathrm{Li} \mathrm{Bo}^{[14]}$.

\subsection{Results and Discussion}

Experiment results and range analysis were shown in Table 3.

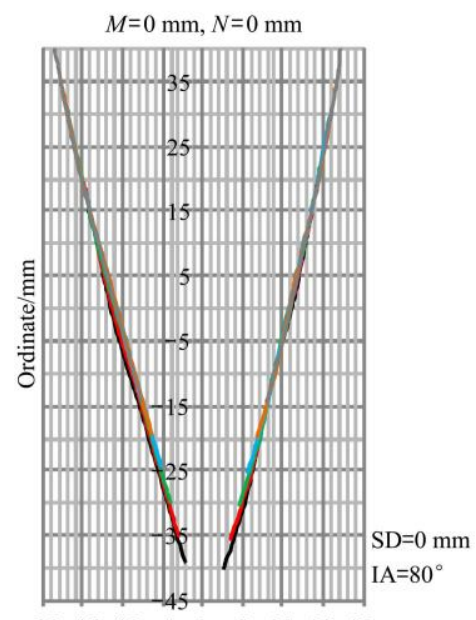

$-20-15-10-5 \quad 0 \quad 5 \quad 10 \quad 15 \quad 20$ Abscissa/mm

$M=0 \mathrm{~mm}, N=0.5 \mathrm{~mm}$

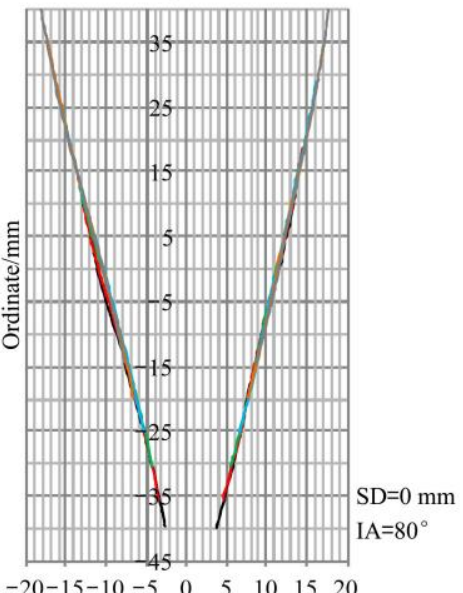

Abscissa/mm

$M=0 \mathrm{~mm}, N=1 \mathrm{~mm}$

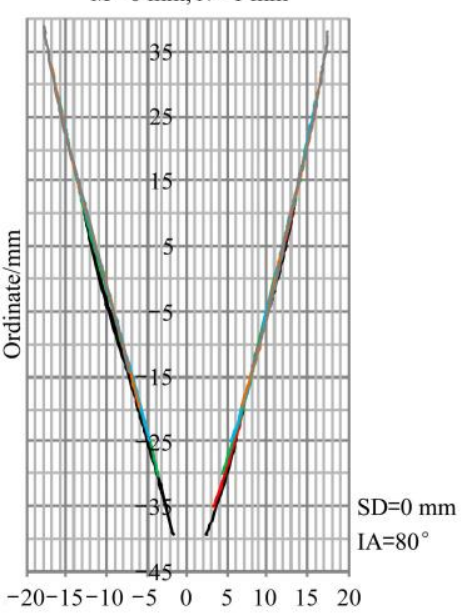

Abscissa/mm

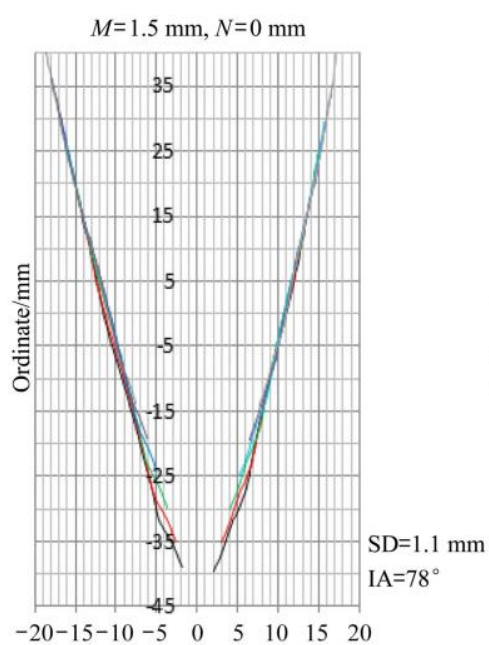

Abscissa/mm

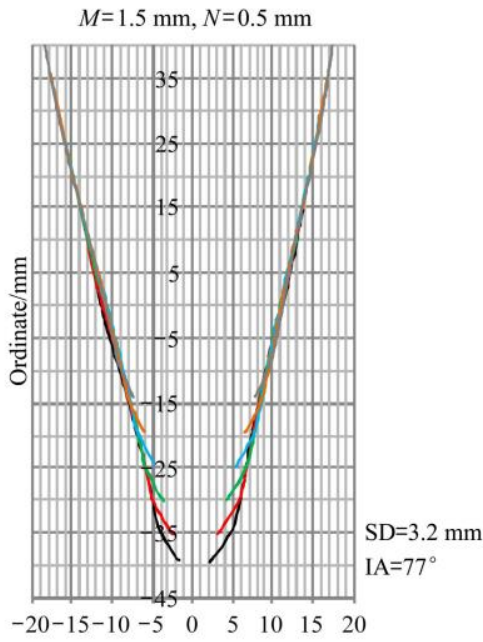

Abscissa/mm

$M=1.5 \mathrm{~mm}, N=1 \mathrm{~mm}$

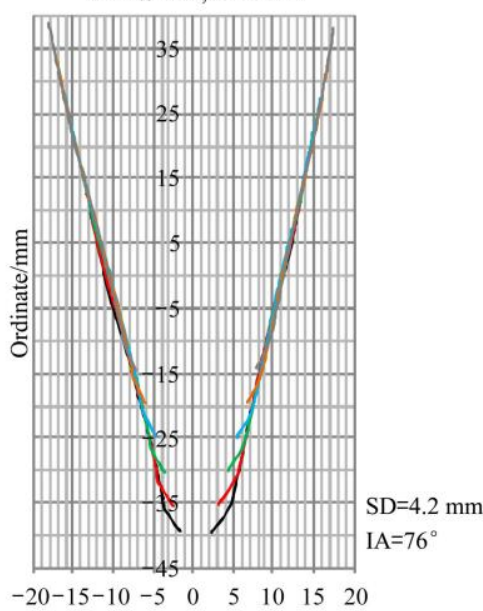

Abscissa/mm
Based on the range analysis in Table 3, SD had a positive correlation with LF value higher as LF increases by $2.62 \mathrm{~N}$ with higher SD. RDR also showed positive correlation with LF value higher as LF increases by $0.51 \mathrm{~N}$ with higher SD. There is no correlation between SD and root distribution on LF. The max value of LF is $4.27 \mathrm{~N}$ when $\mathrm{SD}$ is $4.2 \mathrm{~mm}$ and RDR is $(92 \pm 3.5) \%$. However, optimal combination of effecting factors should take into consideration of both lifting force and transplanting success rate.
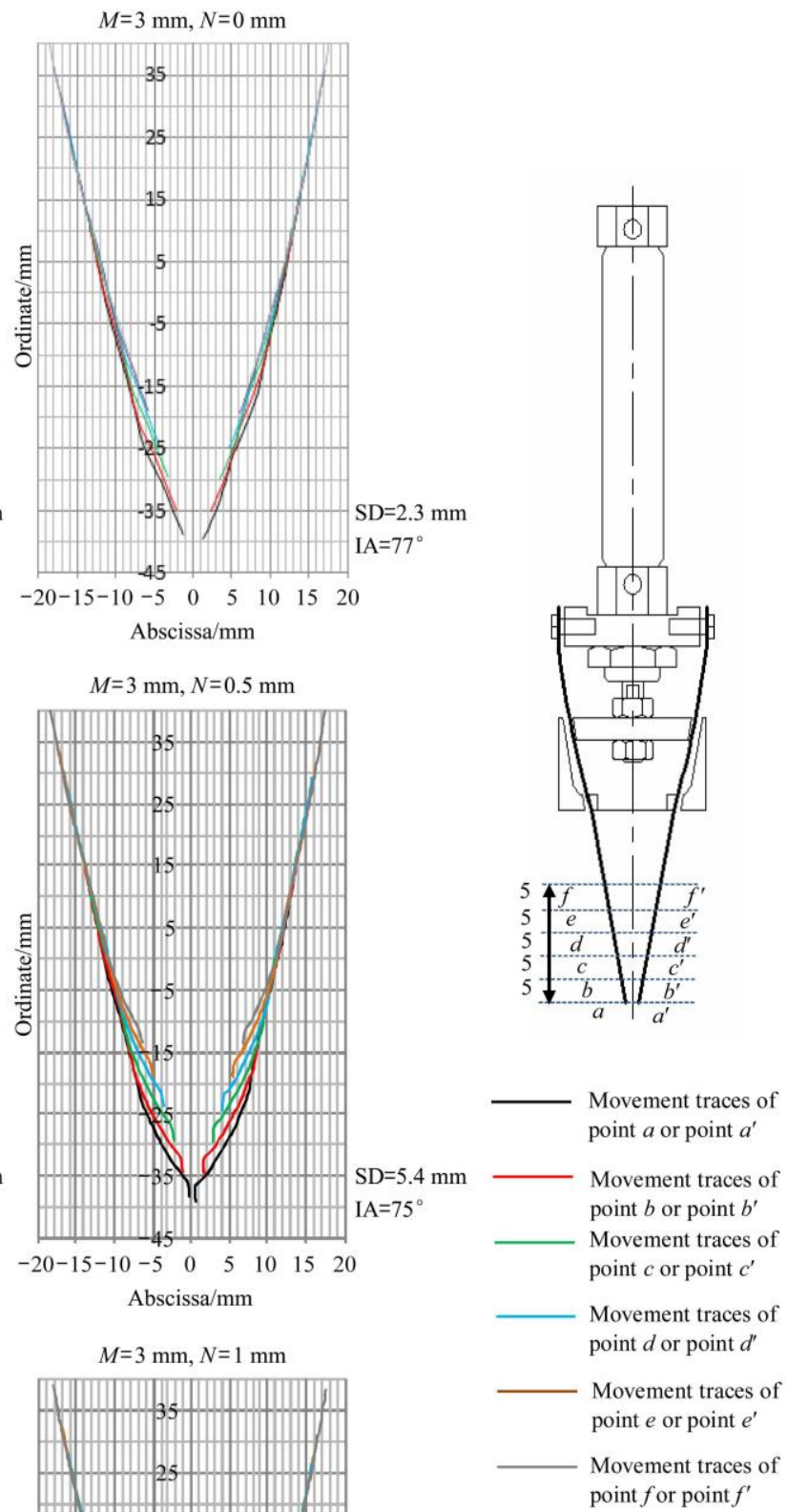

SD: Shrinking distance of steel finger

IA: Inclination angle of steel finger

Figure 7 Shrinking traces of steel finger under different conditions 

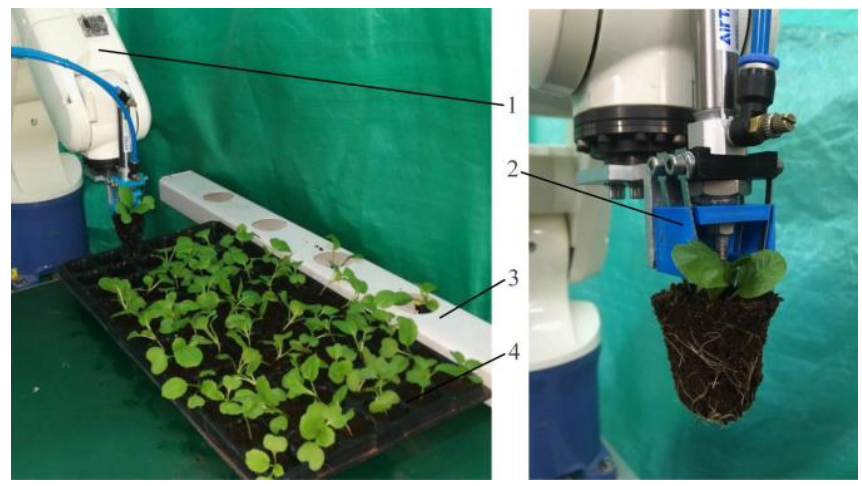

1. Robotic arm 2. Transplanting manipulator 3. Culture duct 4. Plug tray Figure 8 Picking test of transplanting manipulator for leafy vegetable seedlings

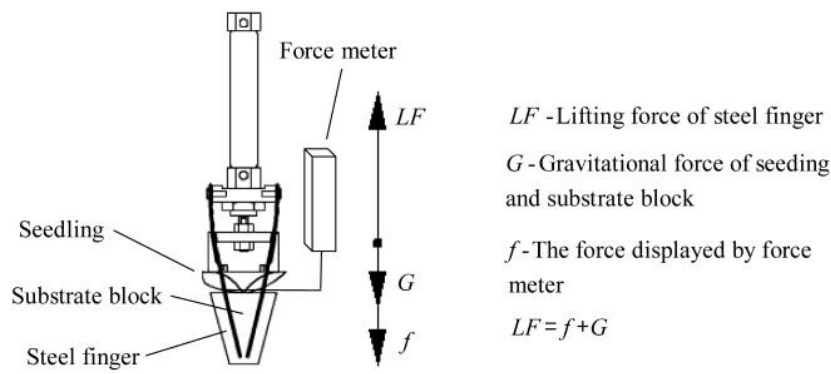

Figure 9 Measurement of lifting force for steel fingers

Table 2 Orthogonal experiment factors and level of transplanting manipulator work capability

\begin{tabular}{ccc}
\hline \multirow{2}{*}{ Level } & \multicolumn{2}{c}{ Factors } \\
\cline { 2 - 3 } & Shrinking distance/mm & Root distribution rate/\% \\
\hline 1 & 0 & $46 \pm 5.1$ \\
2 & 3.2 & $80 \pm 4.6$ \\
3 & 4.2 & $92 \pm 3.5$ \\
\hline
\end{tabular}

Table 3 Orthogonal experiment results and range analysis of transplanting performance for transplanting manipulator

\begin{tabular}{|c|c|c|c|c|c|}
\hline \multirow[b]{2}{*}{ Test No. } & \multicolumn{3}{|c|}{ Effecting factors } & \multirow{2}{*}{$\begin{array}{l}\text { Lifting } \\
\text { force } \\
(L F) \\
/ \mathrm{N}\end{array}$} & \multirow{2}{*}{$\begin{array}{c}\text { Trans-planting } \\
\text { success rate } \\
(T S R) \\
1 \%\end{array}$} \\
\hline & $\begin{array}{l}\text { Shrinking } \\
\text { distance } \\
(S D) / \mathrm{mm}\end{array}$ & $\begin{array}{c}\text { Root } \\
\text { distribution } \\
\text { rate }(R D R) / \%\end{array}$ & $\begin{array}{c}\text { SDx } \\
\text { RDR }\end{array}$ & & \\
\hline 1 & 1 & 1 & 1 & 1.23 & 70.00 \\
\hline 2 & 1 & 2 & 2 & 1.47 & 80.00 \\
\hline 3 & 1 & 3 & 3 & 1.65 & 86.67 \\
\hline 4 & 2 & 1 & 2 & 2.82 & 80.00 \\
\hline 5 & 2 & 2 & 3 & 3.13 & 86.67 \\
\hline 6 & 2 & 3 & 1 & 3.54 & 96.67 \\
\hline 7 & 3 & 1 & 3 & 3.87 & 76.67 \\
\hline 8 & 3 & 2 & 1 & 4.06 & 83.33 \\
\hline 9 & 3 & 3 & 2 & 4.27 & 93.33 \\
\hline$k_{L F 1}$ & 1.45 & 2.64 & 2.94 & & \\
\hline$k_{L F 2}$ & 3.16 & 2.89 & 2.85 & & \\
\hline$k_{L F 3}$ & 4.07 & 3.15 & 2.88 & & \\
\hline Range $R_{L F}$ & 2.62 & 0.51 & 0.09 & & \\
\hline$k_{T S R I}$ & 78.89 & 75.56 & 83.33 & & \\
\hline$k_{T S R 2}$ & 87.78 & 83.33 & 84.44 & & \\
\hline$k_{T S R 3}$ & 84.44 & 92.22 & 83.33 & & \\
\hline Range $R_{T S R}$ & 8.89 & 16.66 & 1.11 & & \\
\hline $\begin{array}{c}\text { Optimal } \\
\text { combination }\end{array}$ & & & & $S D_{3} R D R_{3}$ & $S D_{2} R D R_{3}$ \\
\hline
\end{tabular}

TSR increases by $8.89 \%$ with higher SD value, but TSR did not rise with hither SD value. TSR values are higher when SD at level 2. However, higher RDR can lead TSR value to rise by $16.66 \%$. There is no correlation between SD and root distribution on TSR. The max value of TSR is $96.67 \%$ with SD at $3.2 \mathrm{~mm}$ and root distribution RDR at $(92 \pm 3.5) \%$.

Generally, TSR is affected directly by LF and both move in the same trend. However, at level 3 of SD, TSR does not reach its max value as it does with LF. The reason is that, when shrinking distance of steel finger reaches $4.2 \mathrm{~mm}$, steel finger may stir coco-peat substrate of seedling block. The value of LF is measured immediately after the plug-seedlings are picked up above tray cell. The transplanting success rate measures the successful rate of sending plug-seedlings transported into culture duct. Coco-peat substrate stirred by the fingers might fall down, leading to lower transplanting rate.

The above results showed that, with shrinking steel fingers, lifting force could be enhanced but the plug seedling of coco-peat might be stirred and the TSR would be lowered. Therefore, RDR is an important factor that could protect the substrate block from falling apart. As shown in Table 3, higher RDR leads to higher TSR with constant SD.

Table 1 showed that the pulling forces range from $0.5-1.4 \mathrm{~N}$, similar to the results reported by Han et al. ${ }^{[35]}$ and Miao et al. ${ }^{[36]}$. Our research showed that without steel finger shrinking, the lifting forces of steel fingers are 1.23-1.65 N, comparable to the pulling force. The lifting forces are 2.82-3.54 $\mathrm{N}$ with $3.2 \mathrm{~mm}$ shrinking, and the lifting forces are 3.87-4.27 $\mathrm{N}$ with $4.2 \mathrm{~mm}$ shrinking. Those results showed that suitable steel finger shrinking could increase the lifting force of steel fingers by more than $110 \%$.

Considering both lifting force and transplanting success rate, optimal combination of effecting factors are determined as $\mathrm{SD}_{2} \mathrm{RDR}_{3}$, which means that shrinking distance of steel fingers should be $3.2 \mathrm{~mm}$ while the higher root distribution rate is the better. Thus the root distribution rates of Europe type leafy vegetable plug-seedlings shown in Table 1 are not enough to protect the substrate block from falling apart with 16-day seedling age. The research results suggested that the Europe type leaf vegetable plug-seedlings should be applied about one week later for better transplanting success rate.

\section{Conclusions}

By changing two guidance constraints of elastic steel fingers, it demonstrated that the steel fingers can couple inserting and shrinking by clamping substrate block of hydroponic leafy vegetable plug-seedlings cultured with coco-peat with low density. This new transplanting manipulator can enhance lifting force and stability of picking up seedlings with steel fingers inserting into substrate block using a sole vertical driving air cylinder. With the increase of steel finger' horizontal mounting surface and the width of steel finger guiding part, the steel fingers shrink toward center of plug block. The optimal combination of $M$ and $N$ is $1.5 \mathrm{~mm}$ and $0.5 \mathrm{~mm}$, which results in the shrinking distance of steel fingers at $3.2 \mathrm{~mm}$ and the inserted angle at $77^{\circ}$.

When the substrate moisture is $81 \%$, the shrinking distance of steel fingers increased as the lifting force of the steel fingers increased. When the shrinking distance is $3.2 \mathrm{~mm}$, the lifting force of substrate block rises to $3.16 \mathrm{~N}$ from $1.45 \mathrm{~N}$ when the inserted angle is $80^{\circ}$ with no shrinkage, a nearly $118 \%$ increase. Our research also showed that, the transplanting success rate is $80 \%$ when shrinking distance is $3.2 \mathrm{~mm}$ and root distribution ratio 
is $46 \%$. When the root distribution ratio reached $92 \%$, the transplanting success rate increased to $96.67 \%$. The root distribution ratio has a significant impact on transplanting success rate. Therefore, in order to achieve the acceptable transplanting success rate of transplantation, the root distribution rate of leafy vegetable plug-seedlings should reach about $90 \%$.

\section{Acknowledgements}

The authors acknowledge that this work was supported by the "intelligent agricultural machinery and equipment" of key research and development project in Guangdong Province (2019B020222004), the Guangdong Province modern agriculture innovation team of protected agriculture for generic key technology systems (2019-2023), 2019 South China Agricultural University doctoral innovative talents (domestic training) cultivation project (CX2019N009).

\section{[References]}

[1] Liu S Z, Wang X Y, Gao L H. Nutrition quality and safety of hydroponics vegetables. Agriculture Engineering Technology, 2016; 36(19): 42-45. (in Chinese)

[2] Wang J J, Wang W, Zhao L N, Luan L H, Zhou Y. Application of hydroponics technology in leaf vegetable production. Heilongjiang Agricultural Sciences, 2017; 40(10): 133-136. (in Chinese)

[3] Qin S C, Gu S, Wang Y W. The large-scale mechanical production system of hydroponic leafy vegetables in European. Journal of Agricultural Mechanization Research, 2017; 39(12): 264-268. (in Chinese)

[4] Liu W, Liu J Z. Review of end-effectors in plug seedlings transplanting robot. Journal of Agricultural Mechanization Research, 2013; 35(7): 6-10. (in Chinese)

[5] Yue J K, Guo J X, Liang J, Liang S M, Zhang C, Liu Y, et al. The development status of transplanting machinery at home and abroad. Xinjiang Agricultural Mechanization, 2016; 32(5): 30-32. (in Chinese)

[6] Zhang Y F, Yang Y L, Chu Q, Gu S. Equipment system for horticultural seedling production. Journal of Agricultural Mechanization Research, 2018; 40(10): 257-261. (in Chinese)

[7] Jin X, Li D Y, Ma H, Ji J T, Zhao K X, Pang J. Development of single row automatic transplanting device for potted vegetable seedlings. Int $\mathrm{J}$ Agric \& Biol Eng, 2018; 11(3): 67-75

[8] Nagasaka Y, Umeda N, Kanetai Y, Taniwaki K, Sasaki Y. Autonomous guidance for rice transplanting using global positioning and gyroscopes. Computers and Electronics in Agriculture, 2014; 43(3): 223-234.

[9] Qi F, Zhou X Q, Zhang Y F, Li Z. Development of world greenhouse equipment and technology and some implications to China. Transactions of the CSAE, 2008; 24(10): 279-285. (in Chines)

[10] Jin S L, Zhu X Q. Causes and trends of rising labor costs in China. Economic Review, 2013; 29(2): 37-42. (in Chinese)

[11] Yi S J, Liu Y F, Wang C, Tao G X, Liu H Y, Wang R H. Experimental study on the performance of bowl-tray rice precision seeder. Int $\mathrm{J}$ Agric \& Biol Eng, 2014; 7(1): 17-25

[12] Ye B L, Yi W M, Yu G H, Gao Y, Zhao X. Optimization design and test of rice plug seedling transplanting mechanism of planetary gear train with incomplete eccentric circular gear and non-circular gears. Int J Agric \& Biol Eng, 2017; 10(6): 43-55.

[13] Woo S M, Uyeh D D, Sagong M, Ha Y S. Development of seeder for mixed planting of corn and soybeans. Int J Agric \& Biol Eng, 2017; 10(3): 95-101.

[14] Li B, Gu S, Chu Q, Lü Y J, Hu J S, Xie Z J, et al. Design and experiment on manipulator for transplanting leaf vegetables seedling cultivated by coco-peat. Transactions of the CSAE, 2017; 33(14): 18-24. (in Chinese)

[15] Gu S. Present situation and development suggestion of facility horticultural equipment production. Agriculture Engineering Technology, 2018; 38(4): 10-15. (in Chinese)

[16] Kutz L J, Miles G E, Hammer P A, Krutz G W. Robotic transplanting of bedding plants. Trans ASAE, 1987; 30(3): 586-590.

[17] Ting K C, Giacomelli G A, Shen S J. Robot workcell for transplanting of seedlings part I: Layout and materials flow. Trans ASAE, 1990; 33(3): 1005-1010.

[18] Ting K C, Giacomelli G A, Shen S J, Kabala W P. Robot workcell for transplanting of seedlings: part II. End-effector development. Trans ASAE, 1990; 33(3): 1013-1017

[19] Simonton W. Issues in robotic system design for transplant production systems. Transplant Production Systems, 1992:103-116

[20] Gao G H, Feng T X, Li F. Working parameters optimization and experimental verification of inclined- inserting transplanting manipulator for plug seedling. Transactions of the CSAE, 2015; 31(24): 16-22. (in Chinese)

[21] Hu M J, Yin W Q. Experimental research on the deformed sliding needle pick-up device for plug seedlings. Acta Agriculturae Zhejiangensis, 2011 23(1): 154-158. (in Chinese)

[22] Visser International Trade \& Engineering B.V. http://www.visserite.com/ 2018-07-12.

[23] Tea Project B.V. http://www.teaproject.it/. Accessed on [2018-11-21]

[24] Jiang Z H, Jiang H Y, Tong J H. Optimal design of end-effector on automatic plug seedling transplanter. Journal of Zhejiang University Engineering Science, 2017; 51(06): 1119-1125. (in Chinese)

[25] Jiang Z H, Hu Y, Jiang $\mathrm{H}$ Y,Tong J H. Design and force analysis of end-effector for plug seedling transplanter. Plos One, 2017; 12(7): e0180229.

[26] Han L H, Mao H P, Yan L, Hu J P, Huang W Y, Dong L L. Pincette-type end-effector using two fingers and four pins for picking up seedlings. Transactions of the CSAM, 2015; 46(7): 23-30. (in Chinese)

[27] Han L H, Mao H P, Kumi F, Hu J P. Development of a multi-task robotic transplanting workcell for greenhouse seedlings. Applied Engineering in Agriculture, 2018; 34(2): 335-542.

[28] Mao, H P, Han, L H, Hu, J P, Kumi F. Development of a pincette-type pick-up device for automatic transplanting of greenhouse seedlings. Applied Engineering in Agriculture, 2014; 30(4): 547-556.

[29] Zhang L H, Qiu L C, Tian S B, Xiang Q L. Design of a needle clamping claw for plug seedling transplanting. Journal of Shenyang Agricultural University, 2010; 41(2): 235-237. (in Chinese)

[30] Feng Q C, Zhao C J, Jiang K, Fan P F, Wang X. Design and test of tray-seedling sorting transplanter. Int J Agric \& Biol Eng, 2015; 8(2): 14-20.

[31] Gu S. The thought triggered by investigating the horticulture facilities in Dutch. China Flower \& Gardening News, 2018-08-14(S01). (in Chinese)

[32] $\mathrm{Gu} \mathrm{S}$, Equipment and technology for horticultural facilities production. Beijing: China Agriculture Press, 2015. (in Chinese)

[33] Gu S, Yang Y L, Zhang Y F, Qiao X J. Development status of automated equipment systems for greenhouse vegetable seedlings production in Netherlands and its inspiration for China. Transactions of the CSAE, 2013; 29(14): 185-194. (in Chinese)

[34] Gu S, Yang Y L, Zhang Y F. Development status of automated equipment systems for greenhouse potted flowers production in Netherlands. Transactions of the CSAE, 2012; 28(19): 1-8. (in Chinese)

[35] Han L H, Mao H P, Miao X H, Hu J P, Yang X J. Design of automatic picking up seedling end-effector based on mechanical properties of plug seedlings. Transactions of the CSAM, 2013; 44(11): 260-265. (in Chinese)

[36] Miao X H, Mao H P, Han L H, Sun H, Yang X J, Huang H. Analysis of influencing factors on force of picking plug seedlings and pressure resistance of plug seedlings. Transactions of the CSAM, 2013; 44(S1): 27-32. (in Chinese) 